\title{
Activation of Heat Shock Proteins by Nanocurcumin to Prevent Neurodegenerative Diseases
}

\section{Panchanan Maiti ${ }^{*}$ and Jayeeta Manna ${ }^{2}$}

${ }^{1}$ Department of Neurology, University of Tennessee Health Science Center, Memphis, TN 38163, USA

${ }^{2}$ Department of Physiology, University of Tennessee Health Science Center, Memphis, TN 38163, USA

"Corresponding author: Panchanan Maiti, Department of Neurology, University of Tennessee Health Science Center, 855 Monroe Avenue, Johnson Bldg., Room 402 , Memphis, TN 38163, USA, Tel: 9012462649; E-mail: panchananm@gmail.com

Received date: Jul 16, 2014, Accepted date: Aug 5, 2014, Published date: Aug 18, 2014

Copyright: ( 2014 Maiti P, et al. This is an open-access article distributed under the terms of the Creative Commons Attribution License, which permits unrestricted use, distribution, and reproduction in any medium, provided the original author and source are credited.

\begin{abstract}
Protein misfolding and its progressive accumulation in central nervous system are the common features and the leading cause of several neurodegenerative diseases. Currently no treatment is available to complete removal of these aggregates and rescue neuronal death, synaptic impairment as well as cognitive deficits. Interesting, the cell itself has a fantastic defense mechanism to remove these aggregates. One such crucial mechanism is molecular chaperones such as heat shock proteins. In general, the larger protein aggregates are removed by this system, and degraded through the proteasome or autophagy pathway. Dysfunction or dysregulation of heat shock system has been observed in several neurological diseases, which severely interfere cellular protein clearance mechanism. Therefore, maintenance or balancing of these endogenous protein clearance pathways is a promising approach to remove these protein aggregates. Several small molecules, drugs, and phytochemicals have been studied to promote the activation of this system. Recently, as a potent anti-amyloid polyphenol, curcumin has drawn special attention for the treatment of several brain disorders including several neurodegenerative diseases. It is effective to boost cellular protein clearance system; therefore, it is considered one of the most promising compounds to rectify dysfunction of heat shock system in these disorders. Whereas, because of its low water solubility and fast degradation, the bioavailability of curcumin is very poor. Using nanotechnology, recently several research groups formulated "nanocurcumin" to improve its bioavailability and significantly increases it's therapeutic efficacy against cancer, but scanty of data are available about it's role on boosting heat shock system to prevent protein misfolding and neurodegeneration. In this review we will discuss the current knowledge about the importance of nanocurcumin and its pivotal role on activation of heat shock system to combat against neurodegenerative diseases caused by protein misfolding.
\end{abstract}

Keywords: Protein misfolding; Neurodegenerative diseases; Molecular chaperones; Heat shock system; Curcumin; Nanocurcumin.

\begin{abstract}
Abbreviations
HSP: Heat Shock Protein, HSS: Heat Shock System; HTT: Huntingtin, Rnai-Interference Ribonucleic Acid; FDA: Food And Drug Administration; ER: Endoplasmic Reticulum; a $\beta$ : Amyloid Beta Protein; PRPsc: Prion Protein Scrapie Form; PRPc: Prion Protein Common/Cellular; AD: Alzheimer's Disease, PD: Parkinson's Disease; HD: Huntington's Disease, MS: Multiple Sclerosis; Polyq: Poly Glutamine; AIF: Apoptosis Inducing Factor; CMA: Chaperone Mediated Autophagy; TG: Transgenic; KI: Knock In; MTT: 3-(4,5Dimethylthiazol-2-yl)-2,5-diphenyltetrazolium bromide; EC: Effective Concentration; PIB: Pittsburg Compound; FDG: Fluorodeoxyglucose; PET: Positron Emission Tomography; BACE: Beta Secretase; PS1: Presenilin-1; NFTS: Neurofibrillary Tangles; PPM: Parts Per Million; APP: Amyloid Precursor Protein; CHO: Chinese Hamster Ovary; CAG140ki: Cag140 Knock In; TG: Transgenic; APPsw: Amyloid Precursor Protein Swedish Mutation; HTAUTG: Human Tau Transgenic.
\end{abstract}

\section{Introduction}

Abnormal protein aggregation and their dysfunction is the leading cause of neuronal death observed in several neurodegenerative diseases [1-3]. It comprises more than fifty different medically challenged metabolic, neurodevelopmental or neurodegenerative disorders, for which still there is no cure [4]. Most of these diseases are silent killer, progress slowly and persist rest of the life [1]. The cardinal features of most of these devastating diseases are synaptic loss/failure, neurobehavioral abnormalities and executive dysfunctions including impairment of learning and memory. Accumulated knowledge supports the idea that those diseases might start at early stage of life, but manifestations may come at later stage especially during aging $[1,5]$. The most common neurodegenerative disease is Alzheimer disease $(A D)$, where amyloid beta protein $(A \beta)$ is deposited as senile plaque mainly in extracellular spaces, whereas microtubule stabilizing protein tau is deposited as neurofibrillary tangle (NFT) in intracellular spaces $[1,6]$. Similarly, a-synuclein, huntingtin (HTT), prion are deposited in Parkinson's, (PD) Huntington's (HD) and prion diseases respectively [1-6] (Table 1). However, in most of these disorders all these amyloid proteins undergo conformational changes and become misfolded under certain conditions and deposited as insoluble proteinaceous aggregates inside or outside of cells leads to degenerative changes $[1,2,6]$. Therefore, adequate treatment to be started before onset of these diseases in order to prevent later 
Page 2 of 10

downstream toxicity of those protein aggregates. Several investigators have attempted to clear these protein aggregates from cells, but we yet have not achieved with significant solution. Recently, induction of the endogenous protein clearance pathways such as activation or expression of heat shock proteins (HSPs) draw a special attention as therapeutic strategies to remove those abnormal protein aggregates [7].

The heat shock system (HSS) is a highly conserved cellular defence mechanism, which regulates various cellular functions including protein folding, refolding of partially denatured proteins, protein transport across membranes, cytoskeletal organization, degradation of disabled proteins, and apoptosis [8-10]. It also acts as cytoprotective factor against deleterious environmental stresses, and also activates a wide range of client substrates, including kinases, hormone receptors, and transcription factors as well as oncogenic proteins [10,11]. Different HSPs are found to be localized in synapses and axons and misregulated in different brain diseases. They are implicated in regulating disposal of toxic aggregation such as amyloid plaques and NFT in AD [12,13], $\alpha$ - synuclein in PD $[14,15]$, huntingtin (HTT) in HD [12,16-18] and prion protein in Creutzfeldt-Jakob Disease (CJD) or prion diseases $[19,20]$ via multiple mechanisms [21-23]. Several species of HSPs can bind in vitro and/or in vivo directly to tau, independent of tau phosphorylation, facilitating microtubule polymerization, and limiting tau aggregation [24-26]. Overexpression of certain HSPs decrease the amount of insoluble $A \beta$, tau, reduced tau phosphorylation and increased tau stability, promote tau binding to microtubules, and decrease the toxicity in vitro and in vivo [25]. In contrast, down regulation of HSPs by RNA-mediated interference (RNAi) had the opposite effects [12]. Most importantly, HSPs can also bind to mutant HTT [17,27], $\alpha$-synuclein or prion oligomers or prefibrillar structures, thus interfere in formation of their low molecular weight soluble oligomers or higher order insoluble structures respectively $[28,29]$. They also play pivotal role in regulation of ubiquitin proteasome and the autophagic-lysosomal pathways for their precise functions [28-30].
Knowing the broad cytoprotective properties of HSPs, it is important to find out any molecule/drug, which is safe and capable of inducing the heat shock response and prevent neurodegeneration. Curcumin is one such safe and United States Food and Drug Administration (FDA) approved naturally occurring amyloid binding polyphenolic compound. The pleotropic actions of curcumin including anti-amyloidogenic, neuroprotective [31] antioxidant, antiinflammatory, and anti-proliferation [32,33] suggesting that curcumin might be one of the most propitious compound for treatment of brain diseases. Whereas in case of neurodegenerative diseases, the potential roles of curcumin as a drug target are not fully understood [34]. It may modulate different regulatory pathways, signal transduction etc [32]. Recently, several research groups found strong link between curcumin and its positive regulation of HSPs in different neurological diseases $[13,31,35]$. Unfortunately, low solubility and less bioavailability is an important issue for therapeutic use of curcumin. To resolve this problem, several research groups formulated nanocurcumin by mixing curcumin with different combination of lipid nanoparticles [36-38]. In this review, we will discuss the significant details of advantages of nanocurcumin formulation, and its ameliorative effect on common dysfunction of endogenous protein clearance pathways such as heat shock responses to prevent neurodegenerative diseases.

\section{Major Protein-Misfolding Diseases}

Protein misfolding diseases or proteopathies area the class of diseases, which results loss or degeneration and dysfunction of cells, tissues, organs due to accumulation of functionally inactive proteins [1-6]. More than fifty different protein-misfolding diseases have been well characterized and below table we have mentioned very basic information about only four major neurodegenerative diseases (Table1)

\begin{tabular}{|c|c|c|c|c|c|c|}
\hline $\begin{array}{l}\text { Diseases } \\
\text { involved }\end{array}$ & Genes involved & Risk Factors & Proteins & Pathology & Affected Brain Areas & Symptoms \\
\hline Alzheimer's tangle & APP Presnilin-1,2 & Apo E4 & $A ß, T a u$ & Aß-plaque, Tau & Hippocampus, frontal cortex & $\begin{array}{lr}\text { Memory loss } \\
\text { Personality change, } \\
\text { worried, depressed }\end{array}$ \\
\hline $\begin{array}{l}\text { Parkinsons Parkin } \\
\text { UCHL-1,LRRK-2 }\end{array}$ & $\alpha$-synuclein & Tau linkage tau & $\alpha$-synuclein & $\begin{array}{l}\text { Lewy body } \\
\text { tangle }\end{array}$ & Substantia nigra,Striatum PFC & $\begin{array}{l}\text { Impairment of } \\
\text { sensory } \\
\text { coordination, } \\
\text { cognition }\end{array}$ \\
\hline Huntington & Huntington & $\begin{array}{l}\text { No of CAG repeats in } \\
\text { HTT allele }\end{array}$ & $\begin{array}{l}\text { Huntington } \\
\text { cytoplasm } \\
\text { nucleas }\end{array}$ & Inclusion bodies & $\begin{array}{l}\text { StriatumUncontrolled } \\
\text { clumsiness ,Balane impairment }\end{array}$ & $\begin{array}{l}\text { Uncontrolled } \\
\text { clumsiness, Balane } \\
\text { impairment }\end{array}$ \\
\hline Prion & PRNP & $\begin{array}{l}\text { Homozygosity at Prion } \\
\text { codon } 129\end{array}$ & Pr Psc & Prion plaque & Whole CNS & $\begin{array}{l}\text { Memory loss, } \\
\text { Personality change, } \\
\text { movement disorder }\end{array}$ \\
\hline
\end{tabular}

Table 1: Showed four major protein misfolding neurodegenerative diseases, gene involved, risk factors, protein involved, neuropathological signs, affected brain areas, and their symptoms [1-6].

Heat shock system: In general, most eukaryotic cells constitutively express a group of proteins, which have pivotal role in rectifying misfolded proteins known as HSPs $[39,40]$. In healthy organisms, HSPs maintain protein quality control and targeting abnormal or inactive proteins for their degradation [8,25,26,41,42]. Their expression markedly enhanced under extreme heat stimulus and also under certain stress environment $[43,44]$. Expression of several HSPs have been observed in different cellular stimuli and according to the 
Page 3 of 10

approximate molecular size or function, the principal HSPs are categorized into six conserved classes: the small HSPs (15 to $30 \mathrm{kDa}$, HSP10, HSP26/27) and larger HSPs such as HSP40, HSP60, HSP70, HSP90, HSP100/104/110 [43] (Table 2). They are mainly localized in cytoplasm, and also in cellular organelles such as mitochondria, endoplasmic reticulum (ER) and sometimes in the nucleus [45]. Under normal condition, the levels of HSPs are tightly regulated or maintained by local cellular environment, but when the load of misfolded protein aggregates cross the limit, tremendous deterioration of HSPs defense system has been observed and eventually they fail to respond. To cope up with this stress condition, induction of HSS has been noted.

\begin{tabular}{|c|c|c|c|c|c|}
\hline HSPs & $M W(k D a)$ & Localization & Co-localization & Functions & Involved in diseases \\
\hline HSP10, ER, & 10 & $\begin{array}{l}\text { Mitochondria, cytosol, } \\
\text { nucleus }\end{array}$ & $A \beta$ & Protein folding & AD, MS, tauopathies \\
\hline HSP27 & $20-30$ & $\begin{array}{l}\text { Cytosol, ER, nucleus, } \\
\text { HTT, a-synuclein , } \\
\text { Cytosol }\end{array}$ & $\begin{array}{l}\text { Tau, } \quad A \beta, \quad H T T, \quad \alpha- \\
\text { synuclein, Protein folding }\end{array}$ & Protein degradation, $\mathrm{HD}, \mathrm{PD}$ & $A D, H D, P D ~ H S P 40$ \\
\hline HSP60 & 60 & Mitochondria & $A \beta$ & Prevent protein aggregation & $A D$ \\
\hline HSP70 & 70 & $\begin{array}{l}\text { Cytosol, ER, nucleus,, } \\
\text { mitochondria }\end{array}$ & $\begin{array}{l}\mathrm{A} \beta, \quad H T T, \quad \alpha \text {-synuclein, } \\
\operatorname{PrPc}\end{array}$ & Protein folding/unfolding & $A D, H D, P D$, prion, $M S$ \\
\hline HSP90 & 90 & $\begin{array}{l}\text { Cytosol, ER, as } \\
\text { transcription factor }\end{array}$ & $\begin{array}{l}\mathrm{A} \beta, \quad \mathrm{HTT}, \quad \alpha \text {-synuclein, } \\
\operatorname{PrPc}\end{array}$ & Protein degradation \& acts & $A D, P D, H D$ \\
\hline HSP104/110 & $100-110$ & Cytosol, ER & $\alpha$-synuclein, $\operatorname{PrPc}$ & Thermal tolerance & \\
\hline
\end{tabular}

Table 2: Different species of HSPs, their cellular localization and involvement in different neurodegenerative diseases.

In contrast, overproduction of certain HSPs can lead to development of disease including cancer [44]. In addition, they also regulate the ubiquitin proteasome system or the autophagy pathway, hence HSPs play pivotal role in elimination of the most toxic aggregates, the soluble oligomers $[25,46]$. The removal or degradation of cellular debris by HSPs depends on type of proteins, the aggregate size, and their nature of misfolding.

\section{Role of Specific Hsp in Different Neurodegenerative Diseases}

Recent research revealed that soluble oligomers are the main culprit for neuronal death and HSPs can interacts with the most toxic oligomeric precursors and perhaps also with misfolded conformations of monomers [1-6]. Because of their role in protein folding and maturation as well as the renaturation of misfolded proteins, since last few years induction of HSPs has emerged as a potential targets for the treatment of many protein misfolding diseases including neurodegenerative diseases [7,14,44,47]. After synthesis they can be transported to synapses and axons and binds to aggregation or misfolded proteins. Experimental data evidenced that the early synaptic and axonal abnormalities in $\mathrm{AD}, \mathrm{PD}$ and $\mathrm{HD}$ may be reversed by HSPs, (Figure 1), whereas in severe cases or advance stages, it is beyond their control $[12,25,27]$. In case of $\mathrm{AD}$, it is assumed that HSPs may reduce $A \beta$ aggregation by interfering with the amyloid precursor protein (APP) secretory pathway [48]. Among all these HSPs, HSP70 and HSP90 have most prominent in protein degradation [13,21]. Both HSP70 and HSP90 can promote tau solubility and tau binding to microtubules as well as reduce insoluble tau and tau phosphorylation $[13,21]$. Whereas, levels of HSP90 are inversely associated with granular tau oligomers and neurofibrillary tangles (NFTs) in AD [49] and in a mutant tau model [21]. Overexpression of inducible HSP70 reduces soluble and insoluble tau levels in 30- month-old mice [50]. Similarly, HSP70 has been shown to bind to HTT Exon 1 containing a poly glutamine (polyQ) expansion (a hallmark neuropathology observed in HD) in vitro and in yeast [16] and in mammalian cells [17]. It is co-localized with polyQ aggregates in vitro and in vivo, thus HSP70 might prevent aggregation by binding to a polyQ protein $[12,17]$. HSP70 also can inhibit oligomerization and fibril formation and makes $A \beta$, $\alpha$-synuclein, prion, polyQ aggregate more soluble [12]. Recent experimental reports suggested that HSP40 and HSP70 both inhibit amyloid toxicity in cellular models and in vivo. Both of them can inhibit caspase-3 and caspase-9 activity, inhibit apoptoticinducing factor (AIF) in HTT-transfected cells, indicating that they are directly involved in apoptosis [16,51,52]. Further, tau, APP and HTT are caspase substrates and HSPs are known to prevent caspase activation [10,51]. Similarly, HSP90 and its dependent client proteins are crucial for refolding denatured or misfolded tau, $A \beta, \alpha$-synuclein, HTT, prion as well as the conformational maturation of several other nascent polypeptides into their biologically active structures. Not only those, HSPs are also associated with signalling cascades in normal cells [25,30]. Whereas, heat shock cognate 70 (HSC70: a constitutive expressed molecular chaperone) have important role during chaperone-mediated autophagy (CMA) [29,53,54], a special cellular clearance mechanism, which can remove larger amyloid, aggregates. Moreover, HSPs and their co-chaperones direct the misfolded/ aggregated proteins to the degradation machineries such as proteasome system for their efficient degradation [7].

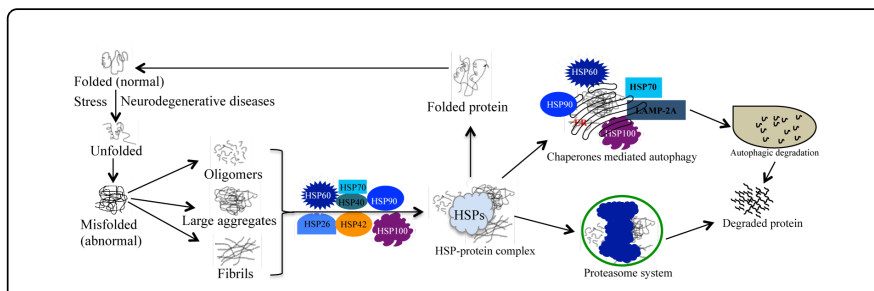

Figure 1: Experimental data evidenced that the early synaptic and axonal abnormalities in $\mathrm{AD}, \mathrm{PD}$ and $\mathrm{HD}$ 


\section{Natural Polyphenols to Activate Heat Shock Response}

There are several interests to investigate natural polyphenols as HSP inducer to prevent neurodegeneration. They are basically nontoxic, safe, easily available, low cost and can be administered orally. Several phenolic compounds derived from traditional medicinal plants have antioxidant, anti-inflammatory properties, but only few of them are potent HSPs activators/modulators. Among them mostly studied is geldanamycin (an antibiotic originated from Streptomyces hygroscopicus) as HSP90 inhibitor [55]. Recently, several other bioactive compounds like curcumin [13], celastrol [56], gambogic acid [57] and withaferin-A [58] have been identified as HSPs modulators. In addition, the adaptogens extracted from roots of Eleutherococcus senticosus, Rhodiola rosea, berry extract from Schisandra chinensis are also reported to increase HSP70 when tested in isolated human neuroglia cells [59]. Similarly, ethanolic leave extracts from Cichorium intybus and Jasminum sambac also induced HSP70 expression in C2C12 myoblasts and rats tissue [60,61]. All these evidences suggested that phytochemical have great impact in prevention of progression of different neurodegenerative diseases.

\section{Curcumin Efficacy in Neurodegenerative Disease Therapy}

Polyphenol curcumin, the yellow curry powder of turmeric is derived from the plant Curcumina longa. Curcumin has been reported to use since more than five thousand years in traditional Ayurvedic medicine of India, China, Vietnam and other South East Asian countries. Whereas, western world have rediscovered its pleotropic beneficial effects since last two decades only. Several experimental data suggested that it can fight against cancer, heart attacks, strokes, arthritis, diabetes, neurodegenerative diseases and many other modern and chronic deceases $[32,38,62-64]$. It is also a precious polyphenol used for clearing scars, treating stomachache, detoxifying liver, and can be used for skin beautification. Its anti-amyloid properties suggest that it might be potent drug for the treatment of several neurodegenerative diseases [62-67]. Recent research reports evidenced that curcumin can be used for spectrum of neurological diseases including $\mathrm{AD}, \mathrm{PD}, \mathrm{MS}$, schizophrenia, depression, epilepsy, cerebral ischemia, brain tumor, and in different neuropathic pain $[32,33,38,64]$ (Figure 2). It can binds and dis-aggregates $A \beta$ oligomers and fibrils and prevents aggregation of this protein in cell free system [63]. Curcumin is anti-inflammatory, antioxidant; stimulate neurogenesis $[31,33,38,68]$. It has been reported to reduce plaque burden and improve cognitive functions in mouse model of $\mathrm{AD}$, and protected against $A \beta$-toxicity in vitro and in vivo [69-74]. Recently, we have shown that curcumin reduces HTT aggregates in CAG140KI mouse model of HD [73]. Similarly, Yang et al. revealed that curcumin were able to decreased $A \beta$ and tau aggregates from $3 \times \mathrm{Tg}$ rat and over expressed human tau-Tg mouse model [63]. In vitro data showed that out of 214-antioxidant compounds curcumin had the strongest inhibitory effect on the formation of $A \beta$ fibrils $[74,75]$.

Further, Ono et al., have reported that curcumin have a dose dependent effects on the inhibition of $A \beta$ aggregation and destabilize preformed fibrils with an EC50 of $0.09-0.63 \mu \mathrm{M}$ [76]. Recent experimental data revealed that oral administration of curcumin could inhibit $A \beta$ oligomerization and tau phosphorylation and improve behavioral impairment of AD animal models $[31,38,63]$. Several other groups also showed that tail vein injection of curcumin for one week had a marked amyloid clearance effect with $30 \%$ plaque size reduction in addition to suppression of dystrophic and aberrant neurites [64].

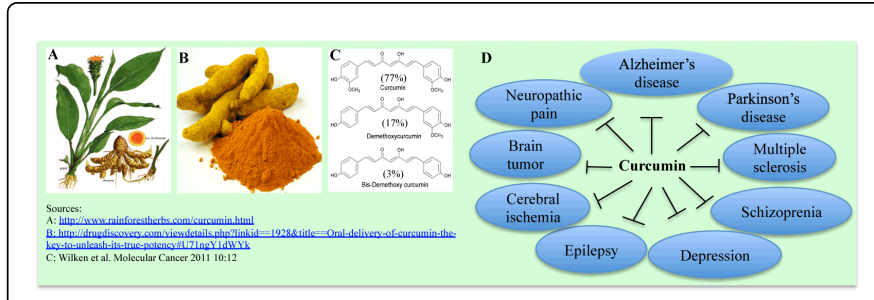

Figure 2: Curcumin source, their derivatives and efficacy in different neurological diseases. A \& B: Curcumin derived from root of plant Curcumin Longa; C: Major compounds from Curcumina Longa; D: Neuroprotective role of curcumin and their derivative in different brain disorders.
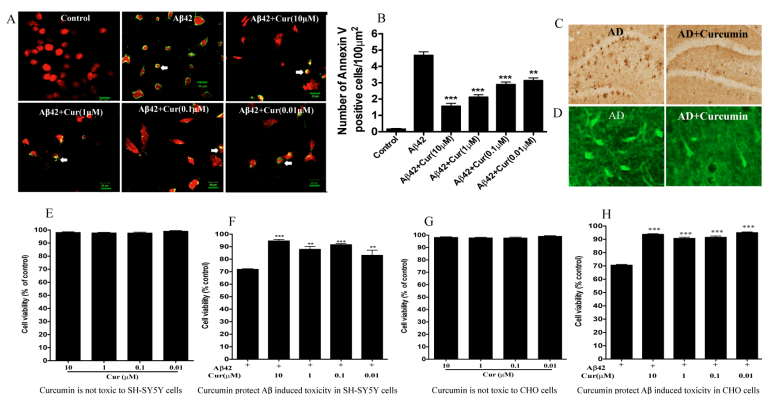

Figure 3: Curcumin inhibits $A \beta 42$ induced neuronal apoptosis in vitro and reduce $A \beta$-plaque load, neurodegeneration in mouse model of AD. A: SH-SY5Y cells were treated with A $\beta 42(10 \mu \mathrm{M})$ and incubated with different doses of curcumin. After 24h of incubation, cells were stained with Annexin-V tagged with FITC and numbers of apoptotic (white arrow) death were counted. Curcumin protected A $\beta 42$ induced neuronal apoptosis (B). Data are mean \pm standard error of mean, ${ }^{* *} \mathrm{p}<0.01,{ }^{* * *} \mathrm{p}<0.001$ compared to $A \beta 42$ treated groups; $C \& D$ : Curcumin decreased $A \beta$-plaque load (hippocampus: 4G8 immunostain) and neurodegeneration (Cortex: Fluoro Jade B staining) in animal model of AD. Figure E$\mathrm{H}$ : Curcumin is safe and having anti-amyloid properties. The Chinese hamster ovary (CHO) (E \& F) and SY-SY5Y (G \& H) cells were treated with different doses of curcumin for $24 \mathrm{~h}$ and cell viability were measured by MTT assay. Curcumin showed no toxicity in all these concentrations in both cell lines. Similarly, these cell lines were insulted with $\mathrm{A} \beta 42(10 \mu \mathrm{M})$ and treated with same doses of curcumin. After $24 \mathrm{~h}$ of incubation, curcumin rescued $\mathrm{A} \beta 42$ induced cell death in both the cell lines. Results are mean \pm standard error of mean, ${ }^{* *} \mathrm{p}<0.01,{ }^{* * *} \mathrm{p}<0.001$ compared to $\mathrm{A} \beta 42$ treated group.

Most importantly, binding affinity of curcumin for $A \beta$ aggregates is as high or higher than successful molecular imaging probes such as Pittsburg compound (PIB), Fluorodeoxyglucose (FDG) [77,78]. Curcumin can also reduce $A \beta$ production by inhibiting beta secretase (BACE), the enzyme responsible for synthesis of $A \beta$ from amyloid precursor protein [79-82]. It also decreases $A \beta$ production by inhibiting GSK-3 $\beta$ (the enzyme responsible for phosphorylation of tau) mediated presinilin-1 activation [83]. It can also stimulate phagocytosis of $\mathrm{A} \beta$ in a rat $\mathrm{AD}$ model [33]. Further, curcumin has been shown to bind with neurofibrillary tangles (NFTs) in human AD 
brain and animals $[84,85]$. It can inhibit tau phosphorylation and aggregation as observed in animal model of AD [74,86]. Similarly, several research groups have shown that curcumin could also bind with other amyloid proteins containing $\beta$-pleated sheet structures including $\alpha$ - synuclein $[87,88]$, HTT $[35,89]$ and prion [90] aggregates and inhibits their oligomerization.

\section{Nanotechnology Approaches to Enhance the Bioavailability of Curcumin}

Because of its potential impact to prevent and treat a wide spectrum of incurable and chronic diseases, nowadays curcumin is globally accepted as one of the wonder drug for future. Most importantly, it is safe up to $12 \mathrm{~g}$ /day as seen in animal studies and in phase-I clinical trial [91]. However, despite its pleotropic action against several diseases, the main drawback of successful use of curcumin therapy in clinical trial is its poor solubility and bioavailability $[32,92,93]$. Basically, most of the free curcumin are instable at cellular $\mathrm{pH}$. After oral administration it becomes glucuronidated in the liver and eliminated from body through urine $[94,95]$. That is why no free curcumin was detected in plasma from patients in a clinical trial with 2 or $4 \mathrm{~g}$ of curcumin administration per day in AD patients [92]. As tissue can absorb very little amount of free curcumin, therefore either high amount of curcumin administration is essential in order to get its beneficial effects or anyhow we need to increase its absorption through elementary system (Figure 4). The main pitfall of use of higher doses of free curcumin, it can destroy normal intestinal flora due to its antibacterial properties, which can increase the risk of indigestion.

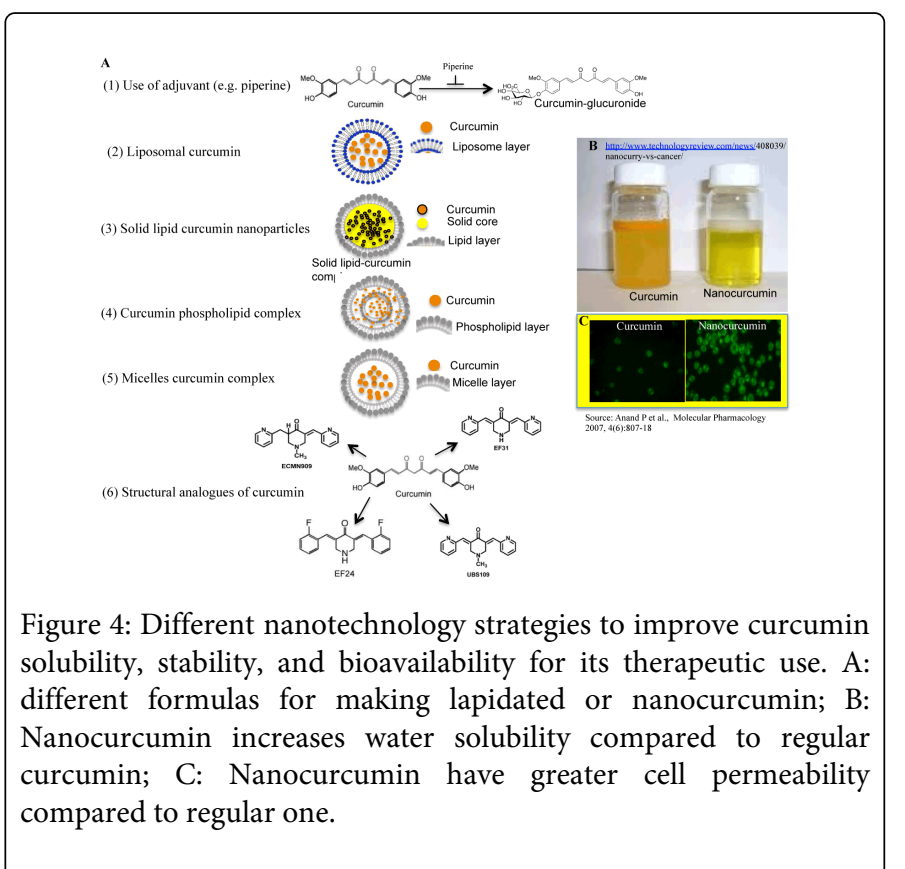

Several other commonly reported side effects of use of high doses of curcumin including stomach upset, diarrhea, nausea, allergic reaction and anti-thrombotic activity [96]. Hence, enhancement of curcumin solubility and stability following its oral bioavailability represents a pharmacological challenge for its therapeutic applications. However, numerous approaches have been undertaken to improve the bioavailability of curcumin including nanotechnology-based novel strategies (Table 3). Recently, introduction of most important technologies including use of adjuvant (e.g. piperine), the use of liposomal curcumin (liposome/micelles); solid lipid curcumin nanoparticles; the use of curcumin phospholipid complex; the use of synthetic structural analogues of curcumin (e.g., EF-24), chelating of curcumin with metals, combination with other dietary agents etc [91] have been successfully used to enhance bioavailability of curcumin. These approaches not only increased curcumin bioavailability, but also reduced its cytotoxicity along with increased cellular uptake, enhanced dissolution rates, excellent blood stability etc $[36,37,87,97]$ (Table 3 ). The adjuvants like piperine is mainly used to interfere with glucuronidation, thus increase prolongation to stay in blood and inhibit its rapid excretion. Whereas liposomes are both hydrophilic and hydrophobic in nature, therefore it is an excellent system for drug delivery, especially curcumin like molecule. The liposome polymers based nanocurcumin have size less than 100 nanometer $(\mathrm{nm})$. It is highly water-soluble, easily absorbed by cell membrane and its bioavailability is increased up to $80-95 \%$, which is 40 times higher than free curcumin $[37,91,98]$.

This formulation appears to be able to achieve this level and is already in clinical trials for cancer, aging as well as $\mathrm{AD}$ and other neurodegenerative diseases $[37,91,98]$. Recently, Bisht et al. have developed a polymer-based nanoparticle called "nanocurcumin". They have reported that the diameter of this particle is less than $100 \mathrm{~nm}$ in size and have similar cellular activity like regular one [36]. Similarly, Tiyaboonchai et al. have developed solid lipid nanoparticles (SLNs) loaded with curcuminoids, which is $450 \mathrm{~nm}$ in size and stable for at least 6 months at room temperature. It can release curcumin product slowly up to12 h in vitro [108]. Furthermore, micelles-curcumin formulation has been reported to greatly improved intestinal absorption of curcumin. Ma et al. reported that polymeric micellecurcumin increase up to 60 -fold biological half-life for curcumin in rats compared to use of polyethylene glycol or dextrose solution to solubilize curcumin [109]. Similarly, curcumin-phospholipid formula has been showed a significant improvement in curcumin bioavailability in vivo. Liu et al., reported that when the rat was administered $100 \mathrm{mg} / \mathrm{kg}$ of curcumin-phospholipid complex orally, after $2.33 \mathrm{~h}$ plasma curcumin level reached to $600 \mathrm{ng} / \mathrm{mL}$, which was two folds more compare to free curcumin. This formula has also increased half-life of curcumin about a 1.5-fold in rat blood [110], whereas Maiti et al., found 3 folds increase with the same formula [37].

\begin{tabular}{|l|l|l|}
\hline Sno & & \\
\hline 1 & Curcumin nanoparticles & $\begin{array}{l}\text { Potential increase antioxidant and anti-hepatoma capacity, improve physicochemical } \\
\text { properties of curcumin [99] }\end{array}$ \\
\hline 2 & Antimicrobial curcumin nanoparticles [100] & Enhance antimicrobial activity compared to the regular curcumin \\
\hline
\end{tabular}




\begin{tabular}{|l|l|l|}
\hline 3 & Solid lipid nanoparticles curcumin complex & $\begin{array}{l}\text { Improve bioavailability and reduce dose (32-155 times) and increase curcumin efficacy } \\
{[101]}\end{array}$ \\
\hline 4 & Nano crystal solid dispersion of curcumin & Enhanced bioavailability along with high photochemical stability [102] \\
\hline 5 & Curcumin phospholipid complex & Increase antioxidant capacity [37] \\
\hline 6 & Nano liposome decoated curcumin & Enhance anti amyloid or anti fibrilogenic activity [103] \\
\hline 7 & Intravenous injection of curcumin nano-emulsion & Enhance solubility (600 fold), dissolution rate (10 fold) [104] \\
\hline 8 & Oil-in water Nano emulsion to encapsulate curcumin & Enhancement of anti-inflammatory activity [37] \\
\hline 9 & Cyclodextrin/curcumin self assembly & Improve bioavailability and delivery [105] \\
\hline 10 & Curcumin loaded biodegradable polymeric micelles & It is an excellent intravenous injectable aqueous formulation \\
\hline 11 & $\begin{array}{l}\text { Curcumin loaded hydrogel nanoparticles potential for colon } \\
\text { carcinoma [106] }\end{array}$ & Increase antimalarial action [107] \\
\hline 12 & $\begin{array}{l}\text { Polymeric nanoparticles encapsulated curcumin } \\
\text { (Nanocurcumin) }\end{array}$ & Effective as the larger amounts of the free compound against pancreatic cancer [36] \\
\hline
\end{tabular}

Table 3: Advantages of use of different nanotechnology strategies for delivery of curcumin. Application of these technologies improved bioavailability and increases the therapeutic efficacy of curcumin.

In addition, scientist developed isomers or analogues of curcumin, which have similar bioactive capacity like curcumin. For example, EF-24 is a lead analogue of curcumin having antitumor activity in vitro and in vivo. After oral and intraperitoneal administration, this compound rapidly absorbed and peak plasma concentration reach up to $1 \mu \mathrm{M}$ within $3 \mathrm{~min}$. The bioavailability of this analogue was $60 \%$ and $35 \%$, after oral and intraperitoneal administration respectively [111]. Bio-conjugation is another promising technique to enhance curcumin uptake and its bioavailability. Mishra et al. have developed a compound called Biocurcumax (BCM-95), which showed increased bioavailability of 7-8 folds and also bioactivity up to $700 \%$ [112]. They have also used curcumin bio-conjugates containing glycine, alanine, and/or piperic acid and found increased cellular permeability and thus enhanced bioavailability [112].

Similarly, since for decade, Cole and Frautschy groups have used different combination of curcumin such as mixed with phosphatidyl choline, olive oil, or stearic acid to increase curcumin solubility and they have found higher levels of curcumin with these formulas in rat's plasma and brain in comparison to regular curcumin [38]. They have analyzed plasma and brain level of curcumin in an animal model and found with 0.1-0.2 $\mu \mathrm{M}$ in plasma and 1-2 $\mu \mathrm{M}$ in brain tissue [38]. Among all these formula, lipidated curcumin used by this groups (Called Longvida developed by Verdure Sciences, Noblesville, IN; www.verduresciences. com) has 11 folds and 4 folds higher plasma and brain level of curcumin respectively compared with equal doses of regular curcumin or curcumin- piperine extracts. Using this lipidated nanoparticle (Longvida), they have shown that this particular formulation decreased $A \beta$ plaque load and improved memory in a mice model of $\mathrm{AD}[13,38,113]$. In another study Cole and Frautschy groups delivered $5 \mathrm{mg}$ lipidated curcumin and achieved more than $2 \mu \mathrm{M}$ brain curcumin levels with in $3 \mathrm{~h}$ of administration [40]. Similarly, they have found up to $5 \mu \mathrm{M}$ of curcumin in mouse brain tissue after two weeks of feeding of 500-parts per million (ppm) curcumin in chow, suggesting oral delivery of lipidated curcumin can achieve the targeted therapeutic tissue levels of curcumin [38]. This is also reminding that the traditional method of dissolving turmeric in fat during cooking in South East Asian people is likely an effective method to improve its solubility and bioavailability. However, the uses of different lipidated formulas including nanoparticle coated curcumin deliveries are in their beginning stage; need much more development for its successful therapeutic use.

\section{Potential Impact of Nanocurcumin in Activation of Heat Shock System}

Despite strong evidence supporting multiple roles of HSPs in amyloid protein degradation [21,24,34,114], knowledge of their dysregulation in different neurodegenerative diseases and their potential as a drug target is unclear. Further, the relationships between the beta-pleated sheet binding of curcumin and removal of these protein aggregates are poorly understood. One possibility is that it is targeting a common endogenous protein clearance pathway, such as the HSP system. Research from Frautschy group support the idea that curcumin administration decreases tau protein aggregation in human tau transgenic (HtauTg) mouse model [13]. They have demonstrated that curcumin has also been shown to reduce soluble tau and increase HSPs in a human tau mouse model [25]. These results indicate that even after tangles are established, tau-dependent dysfunction of the synapses and behavior deficits can be corrected by curcumin treatment $[13,25]$. Therefore, curcumin might be the promising compounds, which can modulate as well as rectify dysregulation of the heat shock response; their co-chaperones and client proteins in different brain disorders need further investigation.

To test the above hypotheses, we have examined the levels of HSPs and their client proteins (HSP90, HSP70, HSC70, HSP60, HSP40, CDC37, P23, FKBP51 etc.) in AD, tauopathies and HD animal models. For AD animal model, triple transgenic rat (Swedish mutation in APP and mutation in presenilin-1 and presenilin-2) was used. For tauopathies, human tau was over expressed (htau-Tg) in mice, whereas for HD animal model, 140-glutamine codon (CAG) was knocked in (CAG140KI), which produce huge HTT neuropil aggregates and showed significant neurobehavioral impairments [35]. Both 
tauopathies and $\mathrm{AD}$ animal models showed significant cognitive and neurobehavioral impairments along with significant neuropathological symptoms $[13,25]$. However, the HD mice were pretreated with $555-$ ppm regular curcumin and rests two are treated with same doses of solid lipid nanoparticle coated curcumin. The reason for choosing low dose of curcumin is because higher doses e.g. more than $1 \mu \mathrm{M}$ levels of curcumin may actually be less beneficial due to the demonstrated toxic effects in an in vitro model of HD [41] and lesser efficacy in reducing amyloid burden in the Tg2576 mouse model of $\mathrm{AD}[20,25,26]$. Further, more than $1 \mu \mathrm{M}$ concentration of curcumin inhibits the proteasome, which may exacerbate the disease, and increased aggregate sizes in vitro in these studies $[20,25,26]$. However, in our study we been found that there were transgene-dependent reductions of HSPs response along with decline some of their client proteins in all these three neurodegenerative animal models, indicating molecular chaperones are highly affected, whereas, curcumin restored transgenic defects of these proteins (unpublished observation).

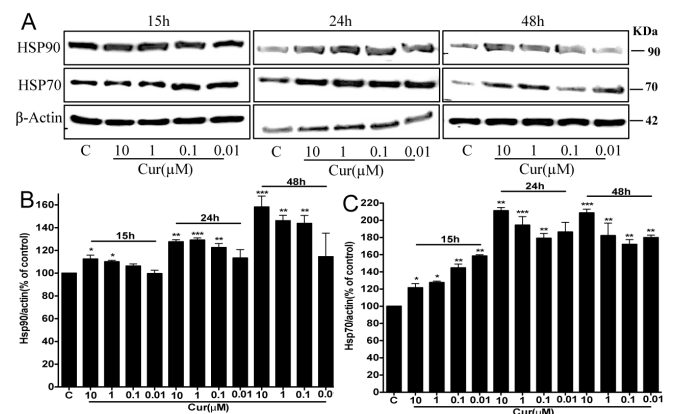

Figure 5: Curcumin induces heat shock response in SH-SY5Y cells. The SH-SY5Y cells were treated with different concentration of curcumin $(\mu \mathrm{M})$ for 15, 24 and $48 \mathrm{~h}$. After 24 and $48 \mathrm{~h}$ of curcumin treatment, HSP90 and HSP70 were significantly increased in compared to control. A: Representative western blot; B \& C: Analysis of optical density of HSP90 and HSP70. Data are mean \pm standard error of mean, ${ }^{*} \mathrm{p}<0.05,{ }^{* *} \mathrm{p}<0.01$ and ${ }^{* * *} \mathrm{p}<0.001$ when compared to control.

In this study the transgene dependent loss of HSP70, HSC70 in CAG140KI, htau-Tg mice and 3xTg rat may represent a failure to compensate for aggregate HTT, tau or A $\beta$ oligomers with aging and be relevant to the removal of those toxic aggregates as well as neuroprotection [24,34]. Another line of interest in this context was whether curcumin could modulate HSP90 co-chaperones and their client proteins. Therefore, we have investigated the levels of CDC37, P23 and FKBP51. In general, CDC37 inhibits the HSP90 activity, whereas P23 and immunophillin FKBP51 activates it. The immunophillin FKBP51 is a mitochondrial protein that translocate to the nucleus to protect cells against oxidative stress [115], and its level has been reported to reduce in $\mathrm{AD}$ brain [116]. It has been observed that CDC37, P23 and FKBP51 were significantly reduced in all the three animal models, suggesting that there was dysregulation of HSP90 co-chaperones, whereas curcumin treatment ameliorated their levels. In addition, to determine whether curcumin can induce the heat shock response in control cells, we have treated CHO and SH-SY5Y cell lines with four different doses ( $\mu \mathrm{M}: 10,1,0.1$ and 0.01 ) of curcumin. It is observed that even $0.01 \mu \mathrm{M}$ of curcumin was able to increase HSP90 and HSP70 after $24 \mathrm{~h}$ of incubation in SH-SY5Y cells (Figure 5). The same doses of curcumin were tested for their toxicity and $A \beta 42$ induced cell death in $\mathrm{CHO}$ and SH- SY5Y cell lines, and it has been observed that all these concentrations of curcumin protected $\mathrm{A} \beta 42$ induced apoptosis (Figure 3). These observations indicate that very low amount of curcumin may be required for neuroprotection as well as to activate cellular HSS, but definitely need further investigations to confirm these findings.

\section{Conclusion}

Accumulation of misfolded proteins in the intra and extracellular spaces of the central nervous system are the leading cause of synaptic loss, neurodegeneration, and cognitive and behavioral impairment in several brain diseases. Endogenous protein clearance pathway such as HSPs have significant role in protein folding and maturation, and renaturation of misfolded proteins, thus play pivotal role to remove these aggregated proteins. This essential system is significantly down regulated in different brain diseases. Maintenance or activation of this system using drug/molecules/compound would be a great strategy to remove these toxic aggregates. Recently, anti-amyloid polyphenol curcumin have been found to be an ameliorative role against amyloid induced dysregulation of HSS. Increase solubility, stability and bioavailability of curcumin by nanocurcumin formulation are the promising strategies for restoration and up-regulation of HSS to rectify the deleterious effect in several neurodegenerative diseases caused by misfolded proteins accumulation.

\section{Acknowledgements}

This work was supported by NIH (RO1AG2175), NIH (RC1AT006816), and NIH grants R01 (NS41574).

\section{Conflict of interest}

There is no conflict of interests.

\section{References}

1. Selkoe DJ (2004) Cell biology of protein misfolding: the examples of Alzheimer's and Parkinson's diseases. Nat Cell Biol 6: 1054-1061.

2. Roychaudhuri R, Yang M, Hoshi MM, Teplow DB (2009) Amyloid betaprotein assembly and Alzheimer disease. J Biol Chem 284: 4749-4753.

3. Haass C, Selkoe DJ (2007) Soluble protein oligomers in neurodegeneration: lessons from the Alzheimer's amyloid beta-peptide. Nat Rev Mol Cell Biol 8: 101-112.

4. Taylor JP, Hardy J, Fischbeck KH (2002) Toxic proteins in neurodegenerative disease. Science 296: 1991-1995.

5. Mucke L, Selkoe DJ (2012) Neurotoxicity of amyloid $\hat{\mathrm{I}}^{2}$-protein: synaptic and network dysfunction. Cold Spring Harb Perspect Med 2: a006338.

6. Shastry BS (2003) Neurodegenerative disorders of protein aggregation. Neurochem Int 43: 1-7.

7. Klettner A (2004) The induction of heat shock proteins as a potential strategy to treat neurodegenerative disorders. Drug News Perspect 17: 299-306.

8. Ellis RJ (2006) Molecular chaperones: assisting assembly in addition to folding. Trends Biochem Sci 31: 395-401.

9. Ellis RJ, van der Vies SM (1991) Molecular chaperones. Annu Rev Biochem 60: 321-347.

10. Takayama S1, Reed JC, Homma S (2003) Heat-shock proteins as regulators of apoptosis. Oncogene 22: 9041-9047.

11. Bagatell R, Whitesell L (2004) Altered Hsp90 function in cancer: a unique therapeutic opportunity. Mol Cancer Ther 3: 1021-1030. 
12. Wyttenbach A (2004) Role of heat shock proteins during polyglutamine neurodegeneration: mechanisms and hypothesis. J Mol Neurosci 23 . 69-96.

13. Ma QL, Zuo X, Yang F, Ubeda OJ, Gant DJ, et al (2013) Curcumin suppresses soluble tau dimers and corrects molecular chaperone, synaptic, and behavioral deficits in aged human tau transgenic mice. The Journal of Biological Chemistry288: 4056-4065.

14. Luo GR, Chen S, Le WD (2006) Are heat shock proteins therapeutic target for Parkinson's disease? Int J Biol Sci 3: 20-26.

15. Auluck PK, Chan HY, Trojanowski JQ, Lee VM, Bonini NM (2002) Chaperone suppression of alpha-synuclein toxicity in a Drosophila model for Parkinson's disease. Science 295: 865-868.

16. Muchowski PJ, Schaffar G, Sittler A, Wanker EE, Hayer-Hartl MK, et al. (2000) Hsp70 and hsp40 chaperones can inhibit self-assembly of polyglutamine proteins into amyloid-like fibrils. Proc Natl Acad Sci U S A 97: 7841-7846.

17. Jana NR, Tanaka M, Wang Gh, Nukina N (2000) Polyglutamine lengthdependent interaction of Hsp40 and Hsp70 family chaperones with truncated $\mathrm{N}$-terminal huntingtin: their role in suppression of aggregation and cellular toxicity. Hum Mol Genet 9: 2009-2018.

18. Hay DG, Sathasivam K, Tobaben S, Stahl B, Marber M, et al. (2004) Progressive decrease in chaperone protein levels in a mouse model of Huntington's disease and induction of stress proteins as a therapeutic approach. Hum Mol Genet 13: 1389-1405.

19. Liu YH, Han YL, Song J, Wang Y, Jing YY, et al. (2011) Heat shock protein 104 inhibited the fibrillization of prion peptide $106-126$ and disassembled prion peptide 106-126 fibrils in vitro. Int J Biochem Cell Biol 43: 768-774.

20. Diedrich JF, Carp RI, Haase AT (1993) Increased expression of heat shock protein, transferrin, and beta 2-microglobulin in astrocytes during scrapie. Microb Pathog 15: 1-6.

21. Dickey CA, Koren J, Zhang YJ, Xu YF, Jinwal UK, et al. (2008) Akt and CHIP coregulate tau degradation through coordinated interactions. Proc Natl Acad Sci U S A 105: 3622-3627.

22. Shimura H, Schwartz D, Gygi SP, Kosik KS (2004) CHIP-Hsc70 complex ubiquitinates phosphorylated tau and enhances cell survival. J Biol Chem 279: 4869-4876.

23. Sarkar M, Kuret J, Lee G (2008) Two motifs within the tau microtubulebinding domain mediate its association with the hsc70 molecular chaperone. J Neurosci Res 86: 2763-2773.

24. Dickey C, Kraft C, Jinwal U, Koren J, Johnson A, et al. (2009) Aging analysis reveals slowed tau turnover and enhanced stress response in a mouse model of tauopathy. Am J Pathol 174: 228-238.

25. Dou F, Netzer WJ, Tanemura K, Li F, Hartl FU, et al. (2003) Chaperones increase association of tau protein with microtubules. Proc Natl Acad Sci U S A 100: 721-726.

26. Wyttenbach A, Carmichael J, Swartz J, Furlong RA, Narain Y, et al. (2000) Effects of heat shock, heat shock protein 40 (HDJ-2), and proteasome inhibition on protein aggregation in cellular models of Huntington's disease. Proc Natl Acad Sci U S A 97: 2898-2903.

27. Bandyopadhyay U, Kaushik S, Varticovski L, Cuervo AM (2008) The chaperone-mediated autophagy receptor organizes in dynamic protein complexes at the lysosomal membrane. Mol Cell Biol 28: 5747-5763.

28. Kaushik S, Cuervo AM (2008) Chaperone-mediated autophagy. Methods Mol Biol 445: 227-244.

29. Matts RL, Brandt GE, Lu Y, Dixit A, Mollapour M, et al. (2011) A systematic protocol for the characterization of Hsp90 modulators. Bioorg Med Chem 19: 684-692.

30. Cole GM, Teter B, Frautschy SA (2007) Neuroprotective effects of curcumin. Adv Exp Med Biol 595: 197-212.

31. Aggarwal BB, Sundaram C, Malani N, Ichikawa H (2007) Curcumin: the Indian solid gold. Adv Exp Med Biol 595: 1-75.

32. Frautschy SA, Hu W, Kim P, Miller SA, Chu T, et al. (2001) Phenolic anti-inflammatory antioxidant reversal of Abeta-induced cognitive deficits and neuropathology. Neurobiol Aging 22: 993-1005.
33. Jinwal UK, O'Leary JC 3rd, Borysov SI, Jones JR, Li Q, et al. (2010) Hsc70 rapidly engages tau after microtubule destabilization. J Biol Chem 285: 16798-16805.

34. Hickey MA, Zhu C, Medvedeva V, Lerner RP, Patassini S, et al. (2012) Improvement of neuropathology and transcriptional deficits in CAG 140 knock-in mice supports a beneficial effect of dietary curcumin in Huntington's disease. Mol Neurodegener 7: 12.

35. Bisht S, Feldmann G, Soni S, Ravi R, Karikar C, et al. (2007) Polymeric nanoparticle-encapsulated curcumin ("nanocurcumin"): a novel strategy for human cancer therapy. J Nanobiotechnology 5: 3 .

36. Maiti K, Mukherjee K, Gantait A, Saha BP, Mukherjee PK (2007) Curcumin-phospholipid complex: Preparation, therapeutic evaluation and pharmacokinetic study in rats. Int J Pharm 330: 155-163.

37. Begum AN, Jones MR, Lim GP, Morihara T, Kim P, et al. (2008) Curcumin structure-function, bioavailability, and efficacy in models of neuroinflammation and Alzheimer's disease. J Pharmacol Exp Ther 326: 196-208.

38. Tutar L, Tutar Y (2010) Heat shock proteins; an overview. Curr Pharm Biotechnol 11: 216-222.

39. Ranford JC, Coates AR, Henderson B (2000) Chaperonins are cellsignalling proteins: the unfolding biology of molecular chaperones. Expert Rev Mol Med 2: 1-17.

40. Söti C, Csermely P (2002) Chaperones and aging: role in neurodegeneration and in other civilizational diseases. Neurochem Int 41: 383-389.

41. Sarto C, Binz PA, Mocarelli P (2000) HSPs in human cancer. Electrophoresis 21: 1218-1226.

42. Powers MV, Workman P (2007) Inhibitors of the heat shock response: biology and pharmacology. FEBS Lett 581: 3758-3769.

43. Bagatell R, Whitesell L (2004) Altered Hsp90 function in cancer: a unique therapeutic opportunity. Mol Cancer Ther 3: 1021-1030.

44. Shimura H, Schwartz D, Gygi SP, Kosik KS (2004) CHIP-Hsc70 complex ubiquitinates phosphorylated tau and enhances cell survival. J Biol Chem 279: 4869-4876.

45. Cataldo AM, Hamilton DJ, Barnett JL, Paskevich PA, Nixon RA (1996) Properties of the endosomal-lysosomal system in the human central nervous system: disturbances mark most neurons in populations at risk to degenerate in Alzheimer's disease. J Neurosci 16: 186-199.

46. Outeiro TF, Klucken J, Strathearn KE, Liu F, Nguyen P, et al. (2006) Small heat shock proteins protect against alpha-synuclein-induced toxicity and aggregation. Biochem Biophys Res Commun 351: 631-638.

47. Johnston JA, Lannfelt L, Wiehager B, O'Neill C, Cowburn RF (1997) Amyloid precursor protein heat shock response in lymphoblastoid cell lines bearing presenilin-1 mutations. Biochim Biophys Acta 1362: 183-192.

48. Sahara N, Maeda S, Yoshiike Y, Mizoroki T, Yamashita S, et al. (2007) Molecular chaperone-mediated tau protein metabolism counteracts the formation of granular tau oligomers in human brain. J Neurosci Res 85 : 3098-3108.

49. Petrucelli L, Dickson D, Kehoe K, Taylor J, Snyder H, et al. (2004) CHIP and Hsp70 regulate tau ubiquitination, degradation and aggregation. Hum Mol Genet 13: 703-714.

50. Ravagnan L, Gurbuxani S, Susin SA, Maisse C, Daugas E, et al. (2001) Heat-shock protein 70 antagonizes apoptosis-inducing factor. Nat Cell Biol 3: 839-843.

51. Gurbuxani S, Schmitt E, Cande C, Parcellier A, Hammann A, et al. (2003) Heat shock protein 70 binding inhibits the nuclear import of apoptosis-inducing factor. Oncogene 22: 6669-6678.

52. Cuervo AM, Dice JF (2000) Age-related decline in chaperone-mediated autophagy. J Biol Chem 275: 31505-31513.

53. Kato K, Ito H, Kamei K, Iwamoto I (1998) Stimulation of the stressinduced expression of stress proteins by curcumin in cultured cells and in rat tissues in vivo. Cell Stress Chaperones 3: 152-160. 
54. He W, Wu L, Gao Q, Du Y, Wang Y (2006) Identification of AHBA biosynthetic genes related to geldanamycin biosynthesis in Streptomyces hygroscopicus 17997. Curr Microbiol 52: 197-203.

55. Zhang YQ, Sarge KD (2007) Celastrol inhibits polyglutamine aggregation and toxicity though induction of the heat shock response. J Mol Med (Berl) 85: 1421-1428.

56. Davenport J, Manjarrez JR, Peterson L, Krumm B, Blagg BS, et al. (2011) Gambogic acid, a natural product inhibitor of Hsp90. J Nat Prod 74: 1085-1092.

57. Grogan PT, Sleder KD, Samadi AK, Zhang H, Timmermann BN, et al. (2013) Cytotoxicity of withaferin A in glioblastomas involves induction of an oxidative stress-mediated heat shock response while altering Akt/ mTOR and MAPK signaling pathways. Invest New Drugs 31: 545-557.

58. Asea A1, Kaur P, Panossian A, Wikman KG (2013) Evaluation of molecular chaperons Hsp72 and neuropeptide $\mathrm{Y}$ as characteristic markers of adaptogenic activity of plant extracts. Phytomedicine 20: 1323-1329.

59. Lee YH, Kim DH, Kim YS, Kim TJ (2013) Prevention of oxidative stressinduced apoptosis of $\mathrm{C} 2 \mathrm{C} 12$ myoblasts by a Cichorium intybus root extract. Biosci Biotechnol Biochem 77: 375-377.

60. Alrashdi AS, Salama SM, Alkiyumi SS, Abdulla MA, Hadi AH, et al. (2012) Mechanisms of Gastroprotective Effects of Ethanolic Leaf Extract of Jasminum sambac against $\mathrm{HCl} /$ Ethanol-Induced Gastric Mucosal Injury in Rats. Evid Based Complement Alternat Med 2012: 786426.

61. Al-Omar FA, Nagi MN, Abdulgadir MM, Al Joni KS, Al-Majed AA (2006) Immediate and delayed treatments with curcumin prevents forebrain ischemia-induced neuronal damage and oxidative insult in the rat hippocampus. Neurochem Res 31: 611-618.

62. Yang F, Lim GP, Begum AN, Ubeda OJ, Simmons MR, et al. (2005) Curcumin inhibits formation of amyloid beta oligomers and fibrils, binds plaques, and reduces amyloid in vivo. J Biol Chem 280: 5892-5901.

63. Garcia-Alloza M, Borrelli LA, Rozkalne A, Hyman BT, Bacskai BJ (2007) Curcumin labels amyloid pathology in vivo, disrupts existing plaques, and partially restores distorted neurites in an Alzheimer mouse model. Journal of Neurochemistry 102: 1095- 1097

64. Bala K, Tripathy BC, Sharma D (2006) Neuroprotective and anti-ageing effects of curcumin in aged rat brain regions. Biogerontology 7: 81-89.

65. Sharma S, Zhuang Y, Ying Z, Wu A, Gomez-Pinilla F (2009) Dietary curcumin supplementation counteracts reduction in levels of molecules involved in energy homeostasis after brain trauma. Neuroscience 161: 1037-1044

66. Wu A, Ying Z, Gomez-Pinilla F (2006) Dietary curcumin counteracts the outcome of traumatic brain injury on oxidative stress, synaptic plasticity, and cognition. Exp Neurol 197: 309-317.

67. Pan MH, Huang TM, Lin JK (1999) Biotransformation of curcumin through reduction and glucuronidation in mice. Drug Metab Dispos 27: 486-494.

68. Kim H, Park BS, Lee KG, Choi CY, Jang SS, et al. (2005) Effects of naturally occurring compounds on fibril formation and oxidative stress of beta-amyloid. J Agric Food Chem 53: 8537-8541.

69. Frautschy SA, Hu W, Kim P, Miller SA, Chu T, et al. (2001) Phenolic anti-inflammatory antioxidant reversal of Abeta-induced cognitive deficits and neuropathology. Neurobiol Aging 22: 993-1005.

70. Lim GP, Chu T, Yang F, Beech W, Frautschy SA, et al. (2001) The curry spice curcumin reduces oxidative damage and amyloid pathology in an Alzheimer transgenic mouse. J Neurosci 21: 8370-8377.

71. Yang F, Lim G. P, Begum A. N, Ubeda O. J, Simmons M. R, et al. (2005) J Biol Chem 280: 5892-5901.

72. Hickey MA, Zhu C, Medvedeva V, Lerner RP, Patassini S, et al. (2012) Improvement of neuropathology and transcriptional deficits in CAG 140 knock-in mice supports a beneficial effect of dietary curcumin in Huntington's disease. Mol Neurodegener 7: 12.

73. Park SY, Kim DS (2002) Discovery of natural products from Curcuma longa that protect cells from beta-amyloid insult: a drug discovery effort against Alzheimer's disease. J Nat Prod 65: 1227-1231.
74. Shytle RD, Bickford PC, Rezai-zadeh K, Hou L, Zeng J, et al. (2009) Optimized turmeric extracts have potent anti-amyloidogenic effects. Curr Alzheimer Res 6: 564-571.

75. Ono K, Hasegawa K, Naiki H, Yamada M (2004) Curcumin has potent anti-amyloidogenic effects for Alzheimer's beta-amyloid fibrils in vitro. J Neurosci Res 75: 742-750.

76. Frautschy SA, Cole GM (2010) Why pleiotropic interventions are needed for Alzheimer's disease. Mol Neurobiol 41: 392-409.

77. Ryu EK, Choe YS, Lee KH, Choi Y, Kim BT (2006) Curcumin and dehydrozingerone derivatives: synthesis, radiolabeling, and evaluation for beta-amyloid plaque imaging. J Med Chem 49: 6111-6119.

78. Narlawar R, Baumann K, Schubenel R, Schmidt B (2007) Curcumin derivatives inhibit or modulate beta-amyloid precursor protein metabolism. Neurodegener Dis 4: 88-93.

79. Morihara T, Teter B, Yang F, Lim GP, Boudinot S, et al. (2005) Ibuprofen suppresses interleukin-1beta induction of pro-amyloidogenic alpha1antichymotrypsin to ameliorate beta-amyloid (Abeta) pathology in Alzheimer's models. Neuropsychopharmacology : official publication of the American College of Neuropsychopharmacology 30: 1111-1120.

80. Lin R, Chen X, Li W, Han Y, Liu P, et al. (2008) Exposure to metal ions regulates mRNA levels of APP and BACE1 in PC12 cells: blockage by curcumin. Neurosci Lett 440: 344-347.

81. Heneka MT, Sastre M, Dumitrescu-Ozimek L, Dewachter I, Walter J, et al. (2005) Focal glial activation coincides with increased BACE1 activation and precedes amyloid plaque deposition in APP[V717I] transgenic mice. J Neuroinflammation 2: 22.

82. Xiong Z, Hongmei Z, Lu S, Yu L (2011) Curcumin mediates presenilin-1 activity to reduce $\hat{\mathrm{I}}^{2}$-amyloid production in a model of Alzheimer's Disease. Pharmacol Rep 63: 1101-1108.

83. Mutsuga M, Chambers JK, Uchida K, Tei M, Makibuchi T, et al. (2012) Binding of curcumin to senile plaques and cerebral amyloid angiopathy in the aged brain of various animals and to neurofibrillary tangles in Alzheimer's brain. J Vet Med Sci 74: 51-57.

84. Tei M, Uchida K, Mutsuga M, Chambers JK, Nakayama H (2012) The binding of curcumin to various types of canine amyloid proteins. The Journal of Veterinary Medical Science / the Japanese Society of Veterinary Science 74: 481-483.

85. Park SY, Kim HS, Cho EK, Kwon BY, Phark S, et al. (2008) Curcumin protected PC12 cells against beta-amyloid-induced toxicity through the inhibition of oxidative damage and tau hyperphosphorylation. Food Chem Toxicol 46: 2881-2887.

86. Ahmad B, Lapidus LJ (2012) Curcumin prevents aggregation in $\hat{\mathrm{I}} \pm$ synuclein by increasing reconfiguration rate. J Biol Chem 287: 9193-9199.

87. Mythri RB, Bharath MM (2012) Curcumin: a potential neuroprotective agent in Parkinson's disease. Curr Pharm Des 18: 91-99.

88. Sandhir R, Yadav A, Mehrotra A, Sunkaria A, Singh A, Sharma S (2014) Curcumin nanoparticles attenuate neurochemical and neurobehavioral deficits in experimental model of Huntington's disease. Neuromolecular Medicine 16: 106-118.

89. Caughey B, Raymond LD, Raymond GJ, Maxson L, Silveira J, et al. (2003) Inhibition of protease-resistant prion protein accumulation in vitro by curcumin. J Virol 77: 5499-5502.

90. Anand P, Kunnumakkara AB, Newman RA, Aggarwal BB (2007) Bioavailability of curcumin: problems and promises. Mol Pharm 4: 807-818.

91. Baum L, Lam CW, Cheung SK, Kwok T, Lui V, et al (2008) Six-month randomized, placebo-controlled, double-blind, pilot clinical trial of curcumin in patients with Alzheimer disease. Journal of Clinical Psychopharmacology

92. Garcea G, Jones DJ, Singh R, Dennison AR, Farmer PB, et al. (2004) Detection of curcumin and its metabolites in hepatic tissue and portal blood of patients following oral administration. Br J Cancer 90: 1011-1015.

93. Ravindranath V, Chandrasekhara N (1981) Metabolism of curcumin-studies with $[3 \mathrm{H}]$ curcumin. Toxicology 22: 337-344. 
Citation: Mait P, Manna J (2014) Activation of Heat Shock Proteins by Nanocurcumin to Prevent Neurodegenerative Diseases. Brain Disord Ther

Page 10 of 10

94. Ravindranath V, Chandrasekhara N (1981) In vitro studies on the intestinal absorption of curcumin in rats. Toxicology 20: 251-257.

95. Burgos-Morón E, Calderón-Montaño JM, Salvador J, Robles A, LópezLázaro M (2010) The dark side of curcumin. Int J Cancer 126: 1771-1775.

96. Rey L (1975) Freezing and freeze-drying. Proc R Soc Lond B Biol Sci 191: 9-19.

97. Flora G, Gupta D, Tiwari A (2013) Nanocurcumin: a promising therapeutic advancement over native curcumin. Crit Rev Ther Drug Carrier Syst 30: 331-368.

98. Gota VS, Maru GB, Soni TG, Gandhi TR, Kochar N, et al. (2010) Safety and pharmacokinetics of a solid lipid curcumin particle formulation in osteosarcoma patients and healthy volunteers. J Agric Food Chem 58: 2095-2099.

99. Yen FL, Wu TH, Tzeng CW, Lin LT, Lin CC (2010) Curcumin nanoparticles improve the physicochemical properties of curcumin and effectively enhance its antioxidant and antihepatoma activities. J Agric Food Chem 58: 7376-7382.

100. Bhawana, Basniwal RK, Buttar HS, Jain VK, Jain N (2011) Curcumin nanoparticles: preparation, characterization, and antimicrobial study. J Agric Food Chem 59: 2056-2061.

101. Kakkar V, Singh S, Singla D, Kaur IP (2011) Exploring solid lipid nanoparticles to enhance the oral bioavailability of curcumin. Mol Nutr Food Res 55: 495-503.

102. Onoue S, Takahashi H, Kawabata Y, Seto Y, Hatanaka J, et al. (2010) Formulation design and photochemical studies on nanocrystal solid dispersion of curcumin with improved oral bioavailability. J Pharm Sci 99: 1871-1881.

103. Mourtas S, Canovi M, Zona C, Aurilia D, Niarakis A, et al. (2011) Curcumin-decorated nanoliposomes with very high affinity for amyloid$\hat{\mathrm{I}}^{2} 1-42$ peptide. Biomaterials 32: 1635-1645.

104. Gao Y, Li Z, Sun M, Guo C, Yu A, et al. (2011) Preparation and characterization of intravenously injectable curcumin nanosuspension. Drug Deliv 18: 131-142.

105. Yallapu MM, Jaggi M, Chauhan SC (2010) Poly(beta-cyclodextrin)/ curcumin self- assembly: a novel approach to improve curcumin delivery and its therapeutic efficacy in prostate cancer cells. Macromolecular Bioscience 10: 1141-1151.
106. Gou M, Men K, Shi H, Xiang M, Zhang J, et al. (2011) Curcumin-loaded biodegradable polymeric micelles for colon cancer therapy in vitro and in vivo. Nanoscale 3: 1558-1567.

107. Dandekar PP, Jain R, Patil S, Dhumal R, Tiwari D, Sharma S (2010) Curcumin-loaded hydrogel nanoparticles: application in anti-malarial therapy and toxicological evaluation. Journal of pharmaceutical sciences99: 4992-5010.

108. Tiyaboonchai W, Tungpradit W, Plianbangchang P (2007) Formulation and characterization of curcuminoids loaded solid lipid nanoparticles. Int J Pharm 337: 299-306.

109. Ma Z, Shayeganpour A, Brocks DR, Lavasanifar A, Samuel J (2007) Highperformance liquid chromatography analysis of curcumin in rat plasma: application to pharmacokinetics of polymeric micellar formulation of curcumin. Biomedical Chromatography : BMC 21: 546-552.

110. Liu A, Lou H, Zhao L, Fan P (2006) Validated LC/MS/MS assay for curcumin and tetrahydrocurcumin in rat plasma and application to pharmacokinetic study of phospholipid complex of curcumin. J Pharm Biomed Anal 40: 720-727.

111. Preetha A, Banerjee R, Huilgol N (2007) Tensiometric profiles and their modulation by cholesterol: implications in cervical cancer. Cancer Invest 25: 172-181.

112. Mishra S, Narain U, Mishra R, Misra K (2005) Design, development and synthesis of mixed bioconjugates of piperic acid-glycine, curcuminglycine/alanine and curcumin-glycine-piperic acid and their antibacterial and antifungal properties. Bioorg Med Chem 13: 1477-1486.

113. Yang Y, Turner RS, Gaut JR (1998) The chaperone BiP/GRP78 binds to amyloid precursor protein and decreases Abeta 40 and Abeta42 secretion. J Biol Chem 273: 25552-25555.

114. Dolan PJ, Johnson GV (2010) A caspase cleaved form of tau is preferentially degraded through the autophagy pathway. J Biol Chem 285: 21978-21987.

115. Smith JR, Workman P (2009) Targeting CDC37: an alternative, kinasedirected strategy for disruption of oncogenic chaperoning. Cell Cycle 8: 362-372.

116. Citri A, Harari D, Shohat G, Ramakrishnan P, Gan J, et al. (2006) Hsp90 recognizes a common surface on client kinases. J Biol Chem 281: 14361-14369. 